\title{
PENGARUH ATRIBUT DAN KUALITAS LAYANAN TERHADAP KEPUASAN PENGUNJUNG DAYA TARIK WISATA PERTANIAN SUBAK DI KOTA DENPASAR BALI
}

\author{
(Effect of Attributes and Service Quality on Visitors Satisfaction in Subak Agricultural Based \\ Tourism Destination in Denpasar City Bali)
}

\author{
I KETUT SURYA DIARTA*) DAN I MADE SARJANA
}

Program Studi Agribisnis, Fakultas Pertanian, Universitas Udayana, Kampus Bukit Jimbaran, Badung, Bali, Indonesia 80361

*Email: suryadiarta@unud.ac.id

Diterima 13 Januari 2020 / Disetujui 12 Mei 2020

\begin{abstract}
Urban subaks developed as tourist destination have strength in their attributes (e.g.agricultural activities, religious rituals, and ease of accessibility), and opportunities to be developed as tourism destination (e.g. as outbound and recreational service providers, huge potential visitors, and external support). However, there is not enough information on how the influence of subak attributes and the quality of services provided in influencing visitor satisfaction. Visitor satisfaction is a key of tourism destination sustainability, including in Subak Padanggalak. This study analyzes: (a) visitor perceptions of Subak Padanggalak as tourism destination, (b) the influence of Subak Padanggalak as tourism destination's attributes and service quality on visitor satisfaction. The study was conducted in Subak Padanggalak, Denpasar City, Bali. The research design uses quantitative analysis, namely SEMPLS with WarpPLS 3.0 software as an analysis tool. Respondents of 100 visitors were selected by convenience sampling. The results showed: (a) the average score of visitors' perception of Subak Padanggalak tourism destination was 3.81 (out of a maximum score of 5.0) which included a good perception category (visitors' perceptions of Subak Padanggalak attributes, service quality, and satisfaction are individually fall into good perception category), (b) the destination attribute variable (X1) and the service quality variable (X2) have a significant and positive effect on visitor satisfaction variables on Subak Padanggalak tourism destination (Y) with R-squared value of 0.533 (or 53.3\%) and classified as moderate effect. It is concluded that Subak Padanggalak meets the expectations of visitors as agriculture-based tourism destination in urban areas because the attributes and quality of services provided are able to satisfy visitors. However, indicators with low score of perception need to be improved to encourage visitors' intention to visit Subak Padanggalak tourism destination.
\end{abstract}

Keywords: attributes, satisfaction, service, subak, tourism

ABSTRAK

Subak sebagai daya tarik wisata (DTW) di perkotaan memiliki kekuatan pada atribut daya tarik wisatanya dan memiliki peluang besar untuk berkembang lebih lanjut. Namun, belum ada informasi yang cukup bagaimana pengaruh atribut DTW subak dan kualitas layanan yang diberikan dalam mempengaruhi kepuasan pengunjung. Kepuasan pengunjung merupakan kunci keberlanjutan sebuah DTW termasuk di Subak Padanggalak. Penelitian ini menganalisis: (a) persepsi pengunjung terhadap DTW Subak Padanggalak, (b) pengaruh atribut dan kualitas layanan terhadap kepuasan pengunjung DTW Subak Padanggalak. Penelitian dilakukan di Subak Padanggalak, Kota Denpasar Bali. Penelitian menggunakan analisis kuantitatif yaitu SEMPLS dengan software WarpPLS 3.0 for Windows. Responden 100 pengunjung dipilih secara convenience sampling. Hasil penelitian menunjukkan bahwa (a) rata-rata pencapaian skor persepsi pengunjung terhadap DTW Subak Padanggalak sebesar 3,81 (dari skor maksimal 5,0) yang termasuk kategori persepsi baik yang didukung oleh rata-rata pencapaian skor persepsi responden terhadap atribut DTW yang tergolong baik, kualitas layanan yang tergolong baik, dan kepuasan terhadap DTW yang juga tergolong baik, dan (b) variabel atribut DTW (X1) dan variabel kualitas layanan DTW (X2) berpengaruh signifikan dan positif terhadap variabel kepuasan pengunjung terhadap DTW Subak Padanggalak (Y) dengan nilai $R$-squared sebesar 0,533 (atau 53,3\%) dan tergolong moderat. Subak Padanggalak disimpulkan memenuhi ekspektasi pengunjung sebagai DTW berbasis pertanian di perkotaan karena atribut dan kualitas layanan yang diberikan mampu memuaskan pengunjung. Namun demikian indikator-indikator yang kurang peranannya perlu diperbaiki agar menjadi pendorong niat pengunjung untuk berkunjung ke DTW Subak Padanggalak.

Kata kunci: atribut, kepuasan, layanan, subak, pariwisata

\section{PENDAHULUAN}

Penelitian Diarta dan Sarjana (2018) menunjukkan bahwa Subak Padanggalak di Kota Denpasar yang dikembangkan sebagai daya tarik wisata (DTW) memiliki kekuatan pada atribut daya tarik wisatanya seperti kegiatan pertaniannya, ritual keagamaan, dan kemudahan aksesibilitas ke subak. Subak di perkotaan juga memiliki peluang dikembangkan sebagai DTW terutama sebagai penyedia layanan outbond dan rekreasi, potensi pengunjung sangat besar, dan adanya dukungan pihak eksternal. Bali memiliki ribuan subak dan sebagian berada di perkotaan seperti di Kota Denpasar. Penelitian ini penting bagi upaya pengembangan subak perkotaan 
sebagai DTW mengingat potensi pasar pengunjung baik pengunjung wisatawan nusantara dan wisatawan mancanegara sangat besar disamping tentunya sebagai sumber pendapatan tambahan bagi petani dan kelembagaan subak. Kajian seperti ini belum pernah dilakukan sehingga menjadi justifikasi yang kuat untuk dilaksanakan.

Permasalahan utama yang dihadapi Subak Padanggalak sebagai DTW adalah laju perkembangannya sebagai DTW sejak tahun 2007 sangat lambat karena penyediaan fasilitas penunjang DTW seperti lintasan jogging, tempat istirahat, toilet, dan tempat swafoto sebagai atraksi penarik pengunjung kurang memadai dibandingkan jumlah pengunjung. Menurut keterangan Ketua (Pekaseh) Subak Padanggalak, I Ketut Losen, geliat kedatangan pengunjung dan aktivitas pasar tani sangat baik ketika baru diresmikan, tetapi sekarang sangat jauh berkurang. Dua permasalahan pokok yang cukup berperan yaitu: (1) perkembangan atribut DTW Subak Padanggalak cenderung tidak ada variasi yang signifikan sejak awal diresmikan, dan (2) kualitas layanan pengelola DTW kepada pengunjung kurang diperhatikan (Diarta dan Sarjana 2018). Pengunjung setelah membayar karcis masuk dan parkir tidak ada informasi apapun dari pengelola mengenai atraksi yang ada dan layanan tambahan yang disediakan. Hal ini menjadi keluhan pengunjung yang belum ditangani dengan baik.

Sejatinya, agar DTW berkembang baik maka wajib mengusahakan kepuasan pengunjung yang sangat ditentukan oleh seberapa baik atribut DTW dan seberapa baik kualitas layanan yang diberikan (Kozak dan Rimington 1999; Lee et al. 2011). Menurut Kozak dan Rimington (1999), atribut destinasi pariwisata sangat menentukan tingkat kepuasan pengunjung. Lebih lanjut, Lee et al. (2011) menyatakan bahwa kualitas layanan kepada pengunjung di destinasi sangat menentukan kepuasannya. Semakin bagus atribut destinasi dan semakin berkualitas layanan yang diberikan kepada pengunjung maka semakin puas pengunjung terhadap destinasi. Kepuasan pengunjung merupakan kunci keberlanjutan sebuah daya tarik wisata (Prayag et al. 2017). Sayangnya, belum terdapat data mengenai ketiga hal tersebut di DTW Subak Padanggalak.

Tulisan ini memaparkan upaya Subak Padanggalak sebagai DTW yang berkelanjutan dengan merekayasa atribut DTW dan kualitas layanan yang dapat memenuhi ekspektasi kepuasan pengunjung. Hal ini diharapkan mampu meningkatkan kesejahteraan anggota subak melalui pendapatan tambahan dari usaha ekonomi pariwisata berbasis subak. Fungsi pariwisata dalam usaha menekan tingkat kemiskinan sudah menjadi amanat Undang Undang No.10/2009 tentang Kepariwisataan (Putra dan Pitana 2010). Dalam konteks Bali, Perda Propinsi Bali No. 2/2012 tentang Kepariwisataan Budaya memberi penguatan pada pengembangan Subak Padanggalak sebagai DTW berbasis budaya. Agar berkelanjutan, maka pengembangan Subak Padanggalak sebagai DTW diarahkan mampu memuaskan bagi pengunjung sehingga visi menekan kemiskinan dapat dicapai.

Pengembangan Subak Padanggalak sebagai DTW yang memuaskan pengunjung memerlukan penataan atribut DTW yang memenuhi ekspektasi pengunjung yang didukung oleh adanya layanan yang baik bagi pengunjung. Sayangnya, posisi atribut DTW Subak Padanggalak dan kualitas layanan yang diterima pengunjung belum ada pengukurannya. Akibatnya, upaya pengembangan DTW Subak Padanggalak yang berkelanjutan melalui usaha memenuhi kepuasan pengunjung kurang memiliki dasar secara akademik. Oleh karenanya, tulisan ini memiliki keutamaan yang tinggi agar DTW Subak Padanggalak memiliki arah pengembangan yang baik. Selain menjadi acuan bagi Subak Padanggalak hasilnya juga bisa menjadi referensi bagi subak-subak lainnya di Bali yang berniat menjadi DTW berbasis subak.

Secara lebih detail, tujuan penulisan yaitu: (a) menganalisis tingkat persepsi pengunjung terhadap atribut DTW, kualitas layanan DTW, dan kepuasan pengunjung terhadap DTW Subak Padanggalak, dan (b) menganalisis pengaruh atribut DTW dan kualitas layanan DTW terhadap kepuasan pengunjung DTW Subak Padanggalak.

Menurut UU No.10/2009 tentang kepariwisataan, daya tarik wisata merupakan segala sesuatu yang memiliki keunikan, keindahan, dan nilai yang berupa keanekaragaman kekayaan alam, budaya, dan hasil buatan manusia yang menjadi sasaran atau tujuan kunjungan wisatawan. Mill dan Morrison (2009) menyatakan bahwa terdapat lima komponen DTW yang diperlukan agar berjalan baik yaitu atraksi (attraction), fasilitas (facilities), infrastruktur (infrastructure), transportasi (transportation), dan hospitality (hospitality) yang disingkat dengan AFITH. Atraksi merupakan elemen utama dari sebuah DTW. Atraksi merupakan segala sesuatu yang bisa disaksikan atau dinikmati oleh wisatawan pada sebuah DTW yang menarik wisatawan untuk berkunjung. Karakteristik sebuah atraksi bisa berupa pemandangan alam seperti pantai, air terjun, gunung, hutan dan lainnya, cuaca dan iklim, budaya, sejarah, etnisitas, dan aksessibilitas. Atraksi wisata sering juga disebut sebagai atribut daya tarik wisata (Chahal dan Devi 2015).

Tourism Western Australia (TWA) mengidentifikasi atribut DTW yang paling signifikan yang mencakup objek/atraksi wisata, aksesibilitas, akomodasi, dan layanan tambahan (Chahal dan Devi 2015). Ketika sebuah atraksi menarik wisatawan datang berkunjung, beberapa fasilitas tentu saja diperlukan untuk memenuhi kebutuhan wisatawan tersebut selama di DTW. Jika pada sebuah destinasi memiliki fasilitas yang kurang, maka hal tersebut tentu saja bisa menyebabkan ketidakpuasan wisatawan. Mill dan Morrison (2009) menyebutkan beberapa fasilitas yang dibutuhkan pada sebuah DTW seperti fasilitas tempat 
tinggal, tempat makan dan minum, fasilitas pendukung berupa tempat laundry, minimarket, tempat souvenir, fasilitas rekreasi, dan juga pusat informasi.

Elemen berikutnya dari sebuah DTW yaitu infrastruktur. Keberadaan atraksi dan fasilitas dirasa belum cukup untuk memenuhi kebutuhan wisatawan sampai dengan infrastruktur dasar diadakan. Mill dan Morrison (2009) mengemukakan infrastruktur terdiri dari semua konstruksi pembangunan bawah tanah dan permukaan tanah sebuah wilayah seperti sistem air, jaringan komunikasi, fasilitas kesehatan, sumber listrik atau energi, saluran drainase, jalan raya, dan juga sistem keamanan.

Elemen DTW lainnya yaitu transportasi. Adapun yang termasuk dalam elemen transportasi yaitu moda transportasi, jalan, terminal, dan juga teknologi. Elemen terakhir sebagai pendukung sebuah DTW yaitu hospitality yaitu keramahtamahan yang ditunjukkan tuan rumah. Hospitality mengacu pada kenyamanan wisatawan selama berada di DTW seperti misalnya keramahtamahan pelayan restoran, senyum oleh pegawai hotel dan juga keramahtamahan penduduk setempat.

Menurut Oliver (2010), ketika sebuah produk tidak sesuai dengan ekpektasi konsumen maka menyebabkan ketidaknyamanan secara psikologi (kecewa) yang bisa berpengaruh terhadap tujuan konsumen di masa yang akan datang. Sebaliknya ketika sebuah produk sesuai ekspektasi maka hal ini bisa menyebabkan konsumen merasa puas sehingga memungkinkan konsumen untuk melakukan pembelian terhadap produk secara berulang kali.

Kotler dan Keller (2009) menyatakan bahwa perilaku konsumen setelah pembelian terhadap suatu barang atau produk tergantung dari kepuasan dan ketidakpuasannya terhadap pembelian produk bersangkutan. Terdapat tiga kemungkinan yaitu konsumen kecewa jika tidak sesuai ekpektasi, puas jika memenuhi ekpektasi, dan sangat puas jika melebihi ekpektasinya.

Kualitas layanan dimaknai sebagai sikap dan hubungan yang dihasilkan dari perbandingan antara harapan dan kinerja. Kualitas layanan menurut Parasuraman et al. (1985) diartikan sebagai persepsi pelanggan terhadap layanan yang diterima. Definisi kualitas layanan termasuk di antaranya memuaskan pelanggan atau melampaui ekspektasi, layanan yang memenuhi kebutuhan wisatawan baik yang dinyatakan atau tersirat, kesesuaian yang jelas dengan spesifikasi persyaratan yang ditawarkan, kesesuaian untuk digunakan dimana produk memenuhi kebutuhan wisatawan dan tidak kurang.

Pengelola daya tarik wisata berusaha untuk meningkatkan kualitas layanan mereka dengan keyakinan akan meningkatkan kepuasan wisatawan. Menurut Spark dan Westgate (2002), layanan yang buruk akan berakibat langsung pada DTW, karena wisatawan akan cenderung mencari DTW lain ketika mereka tidak puas dengan layanan yang didapat. Konsep kualitas layanan yang dikemukakkan oleh Parasuraman et al. (1985) terdapat lima dimensi, yaitu: (a) tangibe (fasilitas fisik, peralatan dan penampilan staff atau personil), (b) reliability (kemampuan untuk menunjukan pelayanan yang dapat diandalkan dan akurat), (c) responsiveness (kerelaan untuk membantu wisatawan dan menyediakan pelayanan yang cepat, (d) assurances (pengetahuan dan kesopanan dari staff atau karyawan dan kemampuan mereka memberikan kepercayaan dan kepercayaan diri kepada wisatawan, dan (e) empathy (kepedulian dan perhatian secara perseorangan manajemen atau perusahan kepada wisatawan).

Kepuasan pelanggan paling sering menjadi topik penelitian di bidang perhotelan dan pariwisata karena memainkan peran penting dalam kelangsungan hidup dan masa depan dari setiap produk dan layanan pariwisata. Oliver (2010) menyatakan bahwa kepuasan merupakan respon atau pendapat konsumen mengenai sebuah produk atau layanan yang menyediakan tingkat kesenangan, apakah produk tersebut memenuhi, tidak memenuhi, atau melebihi tingkat kesenangan konsumen. Kotler dan Keller (2009) secara umum mengartikan kepuasan sebagai rasa senang atau kecewa yang dirasakan konsumen setelah membandingkan produk yang mereka rasakan dengan yang mereka harapkan.

Hasan (2015) menyatakan bahwa kepuasan wisatawan merupakan perbandingan antara apa yang diharapkan dengan tingkat kinerja yang dirasakan. Ketika wisatawan merasakan kinerja produk pariwisata pada destinasi yang mereka kunjungi lebih tinggi dari harapan, maka bisa dikatakan mereka merasa puas. Sebaliknya, jika kinerja produk pariwisata tersebut lebih rendah dari harapan mereka, sudah dipastikan mereka merasa kecewa atau tidak puas. Wilkie (dalam Kusyanda 2018) menyatakan ada lima elemen kepuasan konsumen yaitu harapan (expectation), tampilan (performance), perbandingan (comparison), konfirmasi (confirmation), dan diskonfirmasi (disconfirmation).

\section{METODE PENELITIAN}

Penelitian dilakukan di Subak Padanggalak, Kecamatan Denpasar Timur, Kodya Denpasar yang dipilih secara sengaja (purposive) dengan pertimbangan bahwa Subak Padanggalak sejak tahun 2007 sudah dikembangkan sebagai DTW Subak dari program Desa Budaya Kertalangu tetapi perkembangan subak sebagai DTW sangat lambat sehingga kurang berkontribusi maksimal bagi anggotanya padahal memiliki atribut DTW yang bisa dikembangkan untuk menunjang kemajuan aktivitas pariwisata dalam pemberdayaan subak. Penelitian dilaksanakan pada Maret sampai Oktober 2019.

Sumber data berasal dari data primer dan data sekunder. Data primer berasal dari survei terhadap 100 orang pengunjung DTW Subak Padanggalak menyangkut aspek: (a) karakteristik responden, (b) persepsi terhadap atribut DTW, (c) persepsi terhadap kualitas layanan 
DTW, dan (d) kepuasan responden terhadap DTW Subak Padanggalak. Data sekunder diperoleh dari literatur, laporan, publikasi, dan hasil penelitian sebelumnya yang terkait, dan pencatatan yang dilakukan subak dan instansi pemerintah (Pemerintahan Desa Kertalangu, BPS) atau instansi lainnya yang menunjang penelitian ini seperti dokumentasi Subak Padanggalak, majalah atau koran, dan sebagainya. Data sekunder yang dipergunakan di antaranya gambaran umum Subak Padanggalak, atraksi yang sudah ada, dan data lainnya yang menunjang.

Populasi penelitian adalah pengunjung DTW Subak Padanggalak khususnya mereka yang sudah selesai melakukan aktivitas wisata di DTW. Hal ini dilakukan agar sampel yang terpilih benar-benar mampu menilai dan mengevaluasi pengalaman wisatanya di DTW Subak Padanggalak sehingga data yang diperoleh merupakan post evaluation survey. Tidak ada catatan pasti pada Subak Padanggalak mengenai jumlah pengunjung yang berkunjung ke DTW Subak. Namun, besaran sampel dapat didekati dengan persyarakat alat analisis yang akan dipakai yaitu menurut Ghozali (2014) untuk model persamaan struktural (SEM) berbasis varian atau partial least square (PLS) diatur bahwa jumlah sampel yang direkomendasikan berkisar antara minimal 30 responden sampai 100 responden (Ghozali 2014). Berdasarkan ketentuan tersebut maka jumlah sampel yang akan dijadikan responden adalah 100 orang pengunjung. Hal ini sudah mencukupi kelayakan untuk dilakukan analisis menggunakan software WarpPLS versi 3.0 (Sholihin dan Ratmono 2013). SEMPLS dipergunakan untuk menguji hubungan struktural antar variabel (dimensi) pengukuran. Penentuan responden yang terpilih di lapangan dilakukan dengan teknik convenience sampling dimana responden yang diwawancarai berdasarkan pengunjung yang ditemui di DTW Subak Padanggalak saat penelitian dan bersedia diwawancara.

Variabel pokok terdiri atas tiga variabel (dimensi) yaitu dua variabel eksogenus yaitu (a) atribut daya tarik wisata (X1), (b) kualitas layanan daya tarik wisata (X2), dan satu variabel endogenus yaitu (c) kepuasan wisatawan (Y), sebagaimana dapat disimak dalam Tabel 1. Penelitian ini menggunakan intrumen berupa kuesioner (angket) (Sugiyono 2014). Metode skoring pada kuesioner menggunakan Skala Likert dengan interval nilai 1 sampai 5 (Kinnear 1988 dalam Umar 2002).

Data yang dikumpulkan dari survei akan dianalisis untuk menjawab dua tujuan penelitian. Tujuan penelitian pertama untuk mengetahui tingkat persepsi pengunjung terhadap atribut DTW, kualitas layanan DTW, dan kepuasan pengunjung terhadap DTW Subak Padanggalak dianalisis dengan metode interval kelas (Dayan 1986 dalam Kusyanda 2018).

Tujuan penelitian kedua untuk menganalisis pengaruh atribut DTW dan kualitas layanan DTW terhadap kepuasan pengunjung DTW Subak Padanggalak dianalisis dengan menggunakan model persamaan struktural berbasis PLS (Partial Least Square). Pada penelitian ini digunakan software WarpPLS Versi 3.0. Model persamaan struktural pada dasarnya terdiri dari bagian pengukuran measurement model/outer model dan structural model/inner model. Measurement model/outer model bertujuan untuk mengetahui peranan indikator dalam merefleksikan variabel, sedangkan structural model/inner model bertujuan untuk menguji hubungan antar satu variabel dengan variabel lainnya, baik hubungan langsung (direct) maupun tidak langsung (indirect). Data yang telah dianalisis akan menghasilkan model persamaan struktural yang akan dievaluasi baik dari outer model maupun inner model.

Evaluasi outer model (model pengukuran) dilakukan untuk menilai validitas dan reliabilitas model. Berdasarkan hasil analisis uji validitas konvergen maka dari 37 indikator pengukuran maka 20 indikator memiliki loading factor di atas 0,6 sehingga valid (Tabel 2). Demikian juga uji validitas diskriminan memenuhi syarat (nilai AVE >0,5) sebagaimana dapat disimak dalam Tabel 3.

Pengujian reliabilitas variabel dapat dilihat dari nilai Cronbach Alpha dan nilai Composite Reliability dari masing-masing variabel. Variabel dikatakan memiliki reliabilitas tinggi jika nilai Cronbach Alpha $>0,7$ dan nilai Composite Reliability >0,7. Berdasarkan hasil uji reliabilitas semua variabel reliabel sebagaimana dapat disimak dalam Tabel 4.

Tabel 5 memperlihatkan hasil uji kelayakan model (goodness of fit) penelitian. Menurut Solihin dan Ratmono (2013) ukuran kelayakan model persamaan struktural menggunakan WarpPLS 3.0 menyangkut koefisien determinasi $\left(\mathrm{R}^{2}\right)$, reliabilitas instrumen, validitas diskriminan, full collinearity test, dan validitas prediktif $\left(Q^{2}\right)$

Berdasarkan Tabel 5 terlihat bahwa koefisien determinasi ( $R$-Squared) sebesar 0,533 menunjukkan bahwa varian kepuasan wisatawan terhadap DTW Subak Padanggalak dapat dijelaskan sebesar 53,3\% oleh varian atribut dan varian kualitas layanan DTW Subak Padanggalak yang tergolong moderat (Ghozali 2014).

$Q$-Squared (Stoner-Geisser coefficient) merupakan ukuran non parametrik yang diperoleh dari algoritma blindfolding yang digunakan untuk penilaian validitas prediktif atau relevansi dari sekumpulan variabel laten prediktor pada variabel kriterion. Sebuah model yang baik harus memiliki nilai $Q$-Squared $>0$ atau harus memiliki validitas prediktif lebih besar dari nol. Berdasarkan Tabel 5 terlihat nilai $Q$-Squared sebesar $0,537>0$ yang berarti estimasi model yang dianalisis menunjukkan validitas prediktif yang baik. 
Tabel 1 Variabel, indikator, parameter dan skala pengukuran penelitian

\begin{tabular}{|c|c|c|c|c|c|}
\hline No & Variabel & Indikator & & Parameter & $\begin{array}{c}\text { Skala } \\
\text { pengukuran }\end{array}$ \\
\hline \multirow[t]{18}{*}{1} & \multirow[t]{18}{*}{$\begin{array}{l}\text { Atribut DTW } \\
\text { Subak (X1) }\end{array}$} & \multirow[t]{5}{*}{ Attraction } & $(\mathrm{X} 1.1)$ & $\begin{array}{l}\text { Lansekap subak } \quad \text { yang } \quad \text { indah } \\
\text { (instagramable) }\end{array}$ & \multirow[t]{18}{*}{$\begin{array}{l}\text { Ordinal } \\
\text { (Likert) }\end{array}$} \\
\hline & & & $(\mathrm{X} 1.2)$ & $\begin{array}{l}\text { Kegiatan usaha tani yang masih } \\
\text { berlangsung }\end{array}$ & \\
\hline & & & $(\mathrm{X} 1.3)$ & Ritual keagamaan di subak & \\
\hline & & & $(\mathrm{X} 1.4)$ & Sebagai tempat olahraga dan rekreasi & \\
\hline & & & $(\mathrm{X} 1.5)$ & Tempat outbond dan kumpul keluarga & \\
\hline & & \multirow[t]{5}{*}{ Facilities } & $(\mathrm{X} 1.6)$ & Jalur tracking yang bagus & \\
\hline & & & (X1.7) & Tempat makan dan minum tersedia & \\
\hline & & & $(\mathrm{X} 1.8)$ & Fasilitas tempat main anak & \\
\hline & & & (X1.9) & Tempat mancing & \\
\hline & & & $(\mathrm{X} 1.10)$ & Tempat istirahat tersedia & \\
\hline & & \multirow[t]{3}{*}{ Infrastructures } & $(\mathrm{X} 1.11)$ & Jaringan (signal) komunikasi telpon bagus & \\
\hline & & & $(\mathrm{X} 1.12)$ & Jalan raya menuju ke lokasi bagus & \\
\hline & & & $(\mathrm{X} 1.13)$ & Tempat parkir nyaman & \\
\hline & & \multirow[t]{2}{*}{ Transportation } & (X1.14) & Ketersediaan moda transportasi ke DTW & \\
\hline & & & $(\mathrm{X} 1.15)$ & Biaya jasa transportasi ke DTW & \\
\hline & & \multirow[t]{3}{*}{ Hospitality } & $(\mathrm{X} 1.16)$ & Kenyamanan di DTW & \\
\hline & & & $(\mathrm{X} 1.17)$ & Keramahtamahan petugas DTW & \\
\hline & & & (X1.18) & Keramahtamahan pedagang di STW & \\
\hline \multirow[t]{11}{*}{2.} & \multirow{11}{*}{$\begin{array}{l}\text { Kualitas Layanan } \\
\text { DTW (X2) }\end{array}$} & \multirow[t]{2}{*}{ Tangible } & $(\mathrm{X} 2.1)$ & Kerapihan penampilan karyawan & \multirow{11}{*}{$\begin{array}{l}\text { Ordinal } \\
\text { (Likert) }\end{array}$} \\
\hline & & & $(\mathrm{X} 2.2)$ & Kerapihan dan kebersihan DTW & \\
\hline & & \multirow[t]{3}{*}{ Reliability } & $(\mathrm{X} 2.3)$ & $\begin{array}{l}\text { Menepati janji promosi dengan realitas di } \\
\text { lapangan }\end{array}$ & \\
\hline & & & $(\mathrm{X} 2.4)$ & Pelayanan yang diberikan dapat dipercaya & \\
\hline & & & $(\mathrm{X} 2.5)$ & Harga-harga di DTW jujur dan transparan & \\
\hline & & \multirow[t]{2}{*}{ Responsiveness } & $(\mathrm{X} 2.6)$ & $\begin{array}{l}\text { Kecepatan tanggapan karyawan terhadap } \\
\text { keluhan pengunjung }\end{array}$ & \\
\hline & & & $(\mathrm{X} 2.7)$ & $\begin{array}{l}\text { Mau bertanggung jawab jika ada masalah } \\
\text { pada pengunjung }\end{array}$ & \\
\hline & & \multirow[t]{2}{*}{ Assurance } & $(\mathrm{X} 2.8)$ & Keramahtamahan pengelola & \\
\hline & & & $(\mathrm{X} 2.9)$ & $\begin{array}{l}\text { Komunikasi pengelola dengan } \\
\text { pengunjung berjalan baik }\end{array}$ & \\
\hline & & \multirow[t]{2}{*}{ Emphaty } & $(\mathrm{X} 2.10)$ & $\begin{array}{l}\text { Pengelola yang bersahabat dengan } \\
\text { pengunjung }\end{array}$ & \\
\hline & & & $(\mathrm{X} 2.11)$ & $\begin{array}{l}\text { Memelihara hubungan yang baik dengan } \\
\text { pengunjung }\end{array}$ & \\
\hline \multirow[t]{8}{*}{3.} & \multirow{8}{*}{$\begin{array}{l}\text { Kepuasan } \\
\text { Pengunjung } \\
\text { (Y) }\end{array}$} & Overall & Y1 & Puas terhadap atraksi wisata di DTW & \multirow{8}{*}{$\begin{array}{l}\text { Ordinal } \\
\text { (Likert) }\end{array}$} \\
\hline & & \multirow[t]{7}{*}{ Satisfaction } & $\mathrm{Y} 2$ & Puas terhadap fasilitas pariwisata di DTW & \\
\hline & & & Y3 & $\begin{array}{l}\text { Puas terhadap infrastruktur pendukung } \\
\text { DTW }\end{array}$ & \\
\hline & & & Y4 & $\begin{array}{l}\text { Puas terhadap keramahtamahan pengelola } \\
\text { DTW }\end{array}$ & \\
\hline & & & Y5 & Puas terhadap harga-harga di DTW & \\
\hline & & & Y6 & $\begin{array}{l}\text { Puas terhadap kerapihan dan kebersihan } \\
\text { di DTW }\end{array}$ & \\
\hline & & & Y7 & $\begin{array}{l}\text { Puas terhadap pengelola yang } \\
\text { bertanggung jawab }\end{array}$ & \\
\hline & & & Y8 & Puas terhadap keseluruhan situasi DTW & \\
\hline
\end{tabular}


Tabel 2 Hasil pengujian validitas konvergen indikator penelitian

\begin{tabular}{|c|c|c|c|}
\hline No. & Variabel & Indikator & Nilai Outer Loading \\
\hline \multirow[t]{7}{*}{1} & Atribut DTW & $\mathrm{X} 1.1$ & 0,741 \\
\hline & & $\mathrm{X} 1.4$ & 0,686 \\
\hline & & $\mathrm{X} 1.7$ & 0,690 \\
\hline & & $\mathrm{X} 1.8$ & 0,720 \\
\hline & & $\mathrm{X} 1.16$ & 0,664 \\
\hline & & $\mathrm{X} 1.17$ & 0,768 \\
\hline & & $\mathrm{X} 1.18$ & 0,684 \\
\hline \multirow[t]{8}{*}{2} & Layanan DTW & $\mathrm{X} 2.4$ & 0,641 \\
\hline & & $\mathrm{X} 2.5$ & 0,773 \\
\hline & & $\mathrm{X} 2.6$ & 0,689 \\
\hline & & $\mathrm{X} 2.7$ & 0,771 \\
\hline & & $\mathrm{X} 2.8$ & 0,757 \\
\hline & & $\mathrm{X} 2.9$ & 0,797 \\
\hline & & $\mathrm{X} 2.10$ & 0,854 \\
\hline & & $\mathrm{X} 2.11$ & 0,835 \\
\hline \multirow[t]{5}{*}{3} & Kepuasan & $\mathrm{Y} 2$ & 0,692 \\
\hline & & Y5 & 0,719 \\
\hline & & Y6 & 0,743 \\
\hline & & Y7 & 0,635 \\
\hline & & Y8 & 0,745 \\
\hline
\end{tabular}

Tabel 3 Hasil pengujian validitas diskriminan variabel penelitian

\begin{tabular}{|c|c|c|c|}
\hline No & Variabel & AVE & Akar AVE \\
\hline 1. & Atribut DTW & 0,502 & 0,709 \\
\hline 2. & Layanan DTW & 0,589 & 0,767 \\
\hline 3. & Kepuasan & 0,501 & 0,708 \\
\hline
\end{tabular}

Tabel 4 Hasil pengujian reliabilitas variabel penelitian

\begin{tabular}{clcc}
\hline \multicolumn{1}{c}{ Variabel } & Cronbach Alpha & Composite Reliability \\
\hline No & Atribut DTW & 0,834 & 0,876 \\
2. & Layanan DTW & 0,899 & 0,919 \\
3. & Kepuasan & 0,750 & 0,834 \\
\hline
\end{tabular}

Tabel 5 Goodness of fit persamaan struktural

\begin{tabular}{clccc}
\hline No & Kriteria goodness of fit & \multicolumn{3}{c}{ Variabel } \\
\cline { 3 - 5 } & & Atribut & Layanan & Kepuasan \\
\hline 1. & R-Squared & - & - & 0,533 \\
2. & Composite Reliability & 0,876 & 0,919 & 0,834 \\
3. & Cronbach's Alpha & 0,834 & 0,899 & 0,750 \\
4. & Average Variance Extracted & 0,502 & 0,589 & 0,501 \\
5. & Full Collinearity. VIF & 1,807 & 1,837 & 2,048 \\
6. & $Q$-Squared & - & - & 0,537 \\
\hline
\end{tabular}

Full Collinearity VIF merupakan hasil pengujian kolinearitas penuh yang meliputi multikolinearitas vertikal dan lateral. Sebuah model struktural yang baik haruslah memiliki nilai Full Collinearity VIF $<3,3$ sehingga model bebas dari masalah kolinearitas (Solihin dan Ratmono 2013). Berdasarkan Tabel 5 terlihat nilai Full Collinearity VIF semua variabel dalam model pengukuran lebih rendah dari 3,3 yang berarti model yang diajukan terbebas dari masalah kolinearitas.

Secara konseptual, penelitian ini menguji dua hipotesis pokok. Atribut DTW yang baik akan mampu membangun persepsi positif wisatawan terhadap DTW yang bersangkutan sekaligus menjadi pendorong munculnya kepuasan pada DTW. Oleh karenanya diajukan hipotesis penelitian pertama yaitu:

- H1: Atribut DTW yang baik berpengaruh positif dan signifikan terhadap kepuasan pengunjung yang tinggi pada DTW

Di sisi lain, layanan yang baik yang diberikan oleh DTW akan membangun juga persepsi positif pengunjung terhadap DTW yang bersangkutan. Lebih lanjut hal ini mendorong munculnya kepuasan pengunjung atas DTW yang bersangkutan. Oleh karenanya diajukan penelitian kedua yaitu: 
- H2: Kualitas layanan DTW yang baik berpengaruh positif dan signifikan terhadap kepuasan pengunjung yang tinggi pada DTW

Kedua hipotesis di atas (H1 dan $\mathrm{H} 2$ ) akan diuji melalui serangkaian proses pengambilan data dengan alat kuesioner dan dianalisis menggunakan analisis multivariate menggunakan teknik SEMPLS dengan sofware WarpPLS Versi 3.0 for Windows.

\section{HASIL DAN PEMBAHASAN}

\section{Karakteristik Responden}

Berdasarkan tabulasi data, dari 100 orang responden, 46 pengunjung $(46 \%)$ merupakan laki-laki sedangkan 54 pengunjung (54\%) perempuan. Rata-rata umur responden adalah 30,01 tahun dengan kisaran antara 16 tahun sampai dengan 62 tahun. Sebaran profesi pengunjung sangat beragam dengan mayoritas merupakan pelajar/mahasiswa dengan jumlah $38 \%$, disusul oleh pegawai swasta sebesar $29 \%$, ibu rumah tangga sebesar 13\%, wiraswasta sebesar $8 \%$, PNS sebesar $4 \%$, manajer $3 \%$, pedagang $3 \%$ dan konsultan 2\%. Data tersebut menunjukkan bahwa segmen DTW Padanggalak lebih cocok untuk pelajar, mahasiswa, pegawai swasta, ibu rumah tangga dan wiraswastawan.

Sumber utama responden mengetahui keberadaan DTW Subak Padanggalak dari keluarga/teman yaitu sebesar 64\%, kemudian disusul berturut-turut dari internet/sosial media sebesar $22 \%$, pameran pariwisata sebesar 5\%, media cetak sebesar 4\%, travel agent sebesar 3\%, dan TV sebesar 2\%. Data ini menunjukkan peran promosi dari mulut ke mulut masih efektif disamping mulai menguatnya peran internet dan media sosial dalam mempromosikan sebuah DTW yang sedang berkembang.

Dilihat dari frekuensi kunjungan pengunjung ke DTW Subak Padanggalak maka rata-rata sebesar 3,07 kali dengan rentang mulai 1 kali kunjungan (pertama kali berkunjung) sampai dengan paling tinggi 9 kali kunjungan. Frekuensi kunjungan dominan sebanyak 5 kali kunjungan (29\%), disusul berturut-turut sebanyak 1 kali kunjungan (27\%), 2 kali kunjungan (25\%), 4 kali kunjungan (8\%), 3 kali kunjungan (7\%), 8 kali kunjungan (2\%) dan masing-masing $1 \%$ untuk 7 dan 9 kali kunjungan. Data ini juga menunjukkan bahwa $73 \%$ responden telah melakukan kunjungan berulang (lebih dari sekali) yang artinya DTW Subak Padanggalak cukup memenuhi ekspektasi pengunjung. Secara teoritis, orang akan melakukan kunjungan ke suatu DTW secara berulang kali jika mereka cukup puas dan mendapat layanan yang tidak mengecewakan.

\section{Persepsi Pengunjung terhadap Atribut DTW, Kualitas Layanan DTW, dan Kepuasan Pengunjung terhadap DTW Subak Padanggalak}

Pengukuran persepsi pengunjung terhadap DTW Subak Padanggalak diukur melalui tiga variabel yaitu atribut DTW Subak Padanggalak (X1), kualitas layanan (X2), dan kepuasan pengunjung (Y). Berdasarkan hasil penelitian, rata-rata pencapaian skor persepsi pengunjung terhadap DTW Subak Padanggalak sebesar 3,81 (dari skor maksimal 5,0) yang termasuk kategori baik sebagaimana dapat disimak dalam Tabel 6.

Persepsi responden terhadap atribut DTW Subak Padanggalak jatuh pada kategori baik dengan rata-rata skor 3,96 (dari skor maksimal 5,0). Atribut DTW Subak Padanggalak yang baik terutama disebabkan oleh indikator atraksi wisata yang baik dan indikator fasititas penunjang DTW yang juga baik. Subak Padanggalak memiliki hamparan persawahan yang cukup unik karena disediakan jalan akses yang telah dibeton (jalur tracking) sebagai jalan subak yang multi fungsi selain sebagai jalan transportasi petani dan alat pertanian, juga difungsikan sebagai jalur olah raga jalan sehat atau lari serta berfoto dengan latar belakang persawahan di tengah kota. Bagian depan sebelum memasuki lokasi persawahan Subak Padanggalak juga tersedia tempat berkumpul melakukan kegiatan sosial keluarga atau instansi yang mampu menampung cukup banyak orang baik di dalam gedung (wantilan) maupun di lapangan.

DTW Subak Padanggalak juga didukung oleh penyediaan fasilitas penunjang seperti tersedianya tempat istirahat dan adanya beberapa warung makan dan minum yang menyediakan kebutuhan pengunjung selama berwisata, berolahraga atau berekreasi di Subak Padanggalak. Selain tempat beristirahat yang bersifat semi permanen, subak juga menyediakan balai subak yang dilengkapi dengan toilet dan tempat swafoto bagi pengunjung yang menyusuri persawahan. Tempat istirahat ini juga didukung dengan adanya warung masyarakat yang menjual makanan, minuman, dan camilan ringan untuk anak-anak. Penyediaan fasilitas pendukung ini mampu meningkatkan persepsi positif pengunjung terhadap DTW Subak Padanggalak sebagaimana dinyatakan oleh Kozak dan Rimington (1999) yaitu agar DTW berkembangan baik maka wajib mengusahakan kepuasan pengunjung yang sangat ditentukan oleh seberapa baik atribut DTW bersangkutan.

Tabel 6 Persepsi pengunjung terhadap daya tarik wisata Subak Padanggalak

\begin{tabular}{clcc}
\hline Notasi & Parameter & Rata-rata skor & Kategori \\
\hline (X1) & Atribut DTW Subak Padanggalak & 3,96 & Baik \\
(X2) & Kualitas layanan DTW Subak Padanggalak & 3,72 & Baik \\
(Y) & Kepuasan pengunjung pada DTW Subak Padanggalak & 3,74 & Puas \\
\hline \multicolumn{2}{l}{ Rata-rata variabel } & 3,81 & Baik \\
\hline
\end{tabular}


Persepsi responden terhadap kualitas layanan DTW Subak Padanggalak termasuk kategori baik dengan ratarata pencapaian skornya sebesar 3,72 (dari skor maksimal 5,0). Persepsi yang baik ini terutama disebabkan oleh indikator tangible (aspek penampilan pengelola dan DTW) yang dipandang rapi dan bersih yang menunjukkan komitmen DTW untuk memberikan kenyamanan kepada pengunjung. Semakin bagus dalam aspek ini akan menyebabkan tumbuhnya persepsi yang baik pengunjung terhadap DTW (Lee et al. 2011). Kontribusi selanjutnya oleh indikator karamahtamahan, komunikasi yang baik kepada pengunjung dianggap responden menumbuhkan kepercayaan pada DTW secara keseluruhan. Demikian juga sifat bersahabat dan penciptaan hubungan yang baik akan membantu menciptakan kualiatas layanan kepada pengunjung. Tentu, sebuah DTW tidak akan mampu membangun persepsi positif kalau tidak mampu menumbuhkan rasa percaya pengunjung sehingga juga menumbuhkan rasa empati yang kuat karena didukung oleh hubungan yang baik melalui komunikasi yang positif.

Kepuasan pengunjung terhadap DTW Subak Padanggalak masuk dalam kategori puas dengan capaian rata-rata skor sebesar 3,74 (dari skor maksimal 5,0). Hal ini berasal dari penyediaan fasilitas penunjang DTW sehingga pengunjung bisa melakukan aktivitas rekreasi, olah raga, dan jalan-jalan dengan nyaman. Kepuasan pengunjung juga berasal dari kondisi DTW yang cukup bersih dan tertata rapi, keseluruhan situasi di DTW, ramahnya pengelola, dan pengelola yang bertanggung jawab.
Secara umum, temuan di atas sejalan dengan pendapat Kozak dan Rimington (1999) bahwa atribut destinasi pariwisata sangat menentukan tingkat kepuasan pengunjung. Lee et al. (2011) menambahkan bahwa kualitas layanan kepada pengunjung di destinasi sangat menentukan kepuasannya. Semakin bagus atribut destinasi dan semakin berkualitas layanan yang diberikan kepada pengunjung maka semakin puas pengunjung terhadap destinasi (Pandža Bajs 2015). Implikasinya bagi DTW Subak Padanggalak adalah harus lebih bersungguh-sungguh meningkatkan kualitas atribut DTW dan kualitas layanan yang diberikan. Walaupan tingkat hasil penelitian menunjukkan pengunjung puas atas kedua variabel tersebut tetapi kepuasan pengunjung tidak akan bertahan jika atribut dan layanan tidak dikelola dengan baik dan berkualitas.

\section{Pengaruh Atribut DTW dan Kualitas Layanan terhadap Kepuasan Pengunjung DTW Subak Padanggalak}

Gambar 1 dan Tabel 7 menunjukkan output persamaan struktural model penelitian yang menunjukkan bahwa koefisien path pengaruh variabel atribut DTW (X1) terhadap variabel kepuasan pengunjung pada DTW Subak Padanggalak (Y) sangat signifikan yaitu sebesar $0,40(\mathrm{p}<0,01)$. Demikian juga pengaruh variabel kualitas layanan DTW (X2) terhadap variabel kepuasan pengunjung pada DTW Subak Padanggalak (Y) sangat signifikan yaitu sebesar 0,42 ( $<<0,01)$. Data ini menunjukkan hipotesis $1(\mathrm{H} 1)$ maupun hipotesis $2(\mathrm{H} 2)$ diterima.

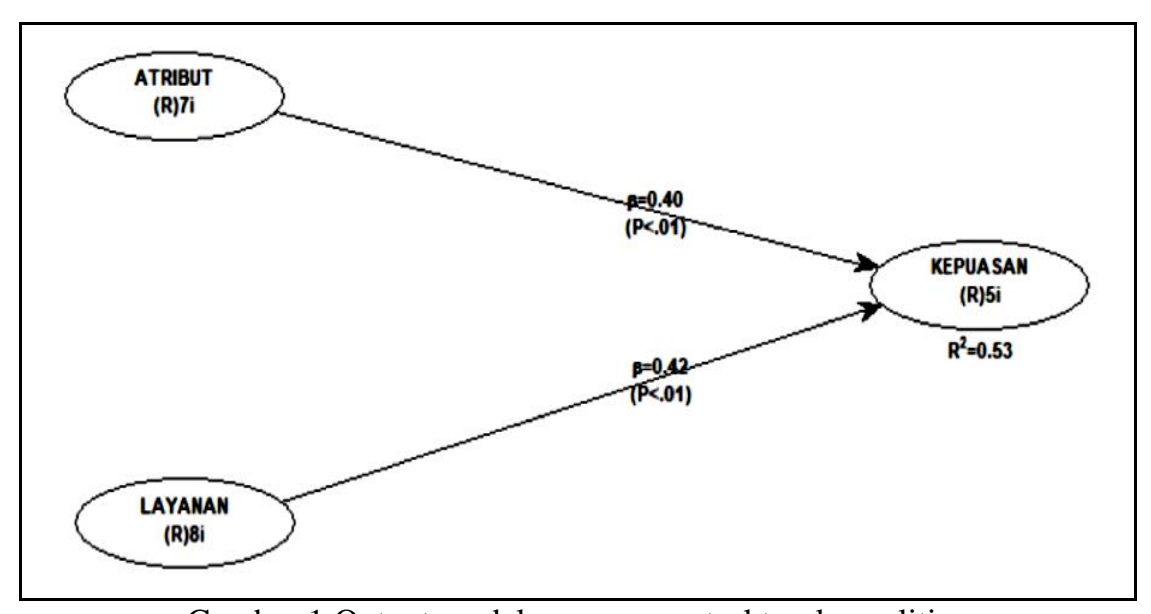

Gambar 1 Output model persamaan struktural penelitian

Tabel 7 Pengaruh langsung variabel eksogenus terhadap variabel endogenus

\begin{tabular}{|c|c|c|c|c|c|c|}
\hline No. & Hipotesis & Var. Eksogenus > Var. Endogenus & $\begin{array}{c}\text { Path } \\
\text { Coefficient }\end{array}$ & $\begin{array}{l}\text { Effect } \\
\text { Size }\end{array}$ & $\begin{array}{c}\text { Standar } \\
\text { Error }\end{array}$ & $P$ Value \\
\hline 1. & H1 & Atribut DTW $(\mathrm{X} 1)>$ Kepuasan $(\mathrm{Y})$ & 0,399 & 0,257 & 0,081 & $\begin{array}{c}<0,001 \\
(* * *)\end{array}$ \\
\hline 2. & $\mathrm{H} 2$ & $\begin{array}{l}\text { Kualitas Layanan }(\mathrm{X} 2)>\text { Kepuasan } \\
(\mathrm{Y})\end{array}$ & 0,424 & 0,277 & 0,099 & $\begin{array}{c}<0,001 \\
(* * *)\end{array}$ \\
\hline
\end{tabular}




\section{Pengaruh Atribut DTW terhadap Kepuasan Pengunjung}

Variabel atribut DTW berpengaruh sangat positif dan signifikan terhadap kepuasan pengunjung pada DTW Subak Padanggalak dengan Path Coefficient sebesar $0,399$ ( $\mathrm{p}<0,001)$. Semakin baik persepsi pengunjung terhadap atribut DTW Subak Padanggalak maka akan menyebabkan pengunjung semakin puas. Temuan ini mengkonfirmasi (menerima) hipotesis penelitian pertama yang menyatakan bahwa atribut DTW memengaruhi kepuasan pengunjung pada DTW Subak Padanggalak (Kozak dan Rimington 1999; Thiumsak dan Ruangkanjanases 2016).

Jika disimak lebih dalam maka indikator-indikator pembentuk variabel atribut DTW hanya signifikan dan berpengaruh positif $(\mathrm{p}<0,001$ dan outer loading $>0,6$ ) dalam 7 indikator dari 18 indikator pengukuran. Ketujuh indikator yang berpengaruh sangat signifikan tersebut berturut-turut berdasarkan nilai outer loading dari yang terbesar ke terkecil yaitu: (a) X1.17 (keramahtamahan petugas DTW/0,768), (b) X1.1 (lansekap subak yang indah yang instagramable/0,741), (c) X1.8 (fasilitas tempat main anak/0,720), (d) X1.7 (tempat makan dan minum tersedia/0,690), (e) X1.4 (sebagai tempat olahraga dan rekreasi/0,686), (f) X1.18 (keramahtamahan pedagang di DTW/0,684), dan (g) X1.16 (kenyamanan di DTW/0,664).

Hospitality merupakan salah satu inti dalam pengelolaan DTW. Sifat keramahtamahan merupakan inti dari hospitality. Pengunjung tentu akan merasa hal ini menjadi keunggulan sebuah DTW yang mendorong mereka merasa puas atas pengelolaan sebuah DTW. Hal ini juga terjadi di DTW Subak Padanggalak dimana keramahtamanhan petugas dapat membangun persepsi positif atas DTW dan mendorong kepuasan pengunjung. Positifnya persepsi pengunjung terhadap DTW juga didukung oleh kondisi lansekap persawahan di DTW Subak Padanggalak yang telah ditata cukup rapi. Telah dibangun jalur olahraga (tracking) sebagai sarana menyusuri areal persawahan dan untuk keperluan olahraga bagi keluarga pengunjung. Hal ini merupakan penunjang sikap positif dan mendorong kepuasan pengunjung atas DTW.

DTW Subak Padanggalak juga sudah menyediakan tempat bermain anak-anak yang mendukung rekreasi keluarga dan ini menambah nilai positif DTW. Keperluan makan dan minum pengunjung juga tidak menjadi persoalan karena DTW Subak Padanggalak sudah dilengkapi beberapa warung makan dan warung kopi. Di Sebelah timur Subak Padanggalak terdapat warung rakyat yang menyediakan makanan pasar semacam ketupat, rujak, es, dan camilan kecil lainnya. Sedangkan sebelah barat dekat pintu masuk terdapat beberapa restoran, tempat mancing dan lapangan rekreasi bagi keluarga. Hal ini mendorong kenyamanan pengunjung yang memerlukan makan dan minuman selama kegiatan di DTW Subak Padanggalak sehingga membangun kesan positif bagi pengunjung yang pada akhirnya mendorong kepuasan pengunjung pada DTW.

DTW menyediakan tempat untuk rekreasi dan olahraga bagi keluarga yang cukup nyaman. Tiap pagi dan sore hari, DTW Subak Padanggalak banyak dikunjungi selain untuk keperluan rekreasi keluarga juga banyak dikunjungi untuk tujuan olahraga. Suasana persawahan dan lansekap sawah yang membentang luas dan kalau musim tanam menghijau sangat indah dan menyegarkan dengan udara yang segar di tengah-tengah perkotaan. Hal ini menjadi salah satu pendorong persepsi positif pengunjung terhadap DTW Subak Padanggalak. Hal ini jika terakumulasi dengan penyebab persepsi positif lainnya yang telah dibahas di atas akan menyebabkan kepuasan pengunjung terhadap DTW Subak Padanggalak.

Implikasi bagi pengembangan Subak Padanggalak sebagai DTW ke depan adalah tetap menjaga atribut DTW agar tetap menjadi daya tarik utama yang membangkitkan minat kunjungan. Subak wajib mempertahankan kelestarian dan keasrian lansekap persawahan dan aktivitas usaha tani dan aktivitas sosial petani sebagai atraksi wisata. Penambahan fasilitas penunjang perlu diperhatikan agar mampu menjamin kenyamanan pengunjung yang selain berwisata juga memanfaatkan areal subak sebagai tempat olahraga keluarga. Peran serta pemerintah dan swasta dalam mendukung hal tersebut sangat diperlukan baik melalui bantuan maupun CSR perusahaan.

\section{Pengaruh Kualitas Layanan DTW terhadap Kepuasan Pengunjung}

Variabel kualitas layanan DTW berpengaruh sangat positif dan signifikan terhadap kepuasan pengunjung pada DTW Subak Padanggalak dengan Path Coefficient sebesar 0,424 $(\mathrm{p}<0,001)$. Semakin baik persepsi pengunjung terhadap kualitas layanan DTW Subak Padanggalak maka akan menyebabkan pengunjung semakin puas. Temuan ini mengkonfirmasi (menerima) hipotesis penelitian kedua yang menyatakan bahwa kualitas layanan DTW memengaruhi kepuasan pengunjung pada DTW (Lee et al. 2011).

Indikator-indikator pembentuk variabel kualitas layanan DTW hanya signifikan dan berpengaruh positif ( $p<0,001$ dan outer loading $>0,6)$ dalam delapan indikator dari 11 indikator pengukuran. Kedelapan indikator yang berpengaruh sangat signifikan tersebut berturut-turut berdasarkan nilai outer loading dari yang terbesar ke terkecil yaitu: (a) X2.10 (pengelola yang bersahabat dengan pengunjung/0,854), (b) X2.11 (memelihara hubungan yang baik dengan pengunjung/0,835), (c) X2.9 (komunikasi pengelola dengan pengunjung berjalan baik/0,797), (d) X2.5 (harga-harga di DTW jujur dan transparan/0,773), (e) X2.7 (mau bertanggung jawab jika ada masalah pada pengunjung/0,771), (f) X2.8 (keramahtamahan pengelola/0,757), (g) X2.6 (kecepatan tanggapan 
karyawan terhadap keluhan pengunjung/0,689), dan (h) X2.4 (pelayanan yang diberikan dapat dipercaya/0,641).

Pengunjung suatu DTW akan merasa puas jika mendapatkan layanan yang baik di DTW selama kunjungan atau kegiatan wisatanya. Kualitas layanan membentuk persepsi positif pengunjung dan menjadi dasar membangun kepuasan pada DTW. Dalam kasus DTW Subak Padanggalak terbukti kualitas layanan memengaruhi secara sangat signifikan kepuasan pengunjung pada DTW. Layanan yang baik sendiri berdasarkan hasil penelitian ditentukan oleh sikap yang bersahabat pengelola DTW kepada pengunjung yang menyebabkan pengunjung merasa nyaman dan mendorong mereka merasa puas. Indikator selanjutnya yang berpengaruh atas baiknya kualitas layanan DTW karena adanya hubungan yang baik antara pengelola dengan pengunjung. Misalnya, pengelola bersedia menjelaskan apa saja yang bisa dilakukan oleh pengunjung selama kunjungan di DTW dan menjelaskan atraksi-atraksi serta fasilitas yang dapat dimanfaatkan pengunjung selama kegiatannya di DTW Subak Padanggalak. Layanan lainnya yang membangun kepuasan pengunjung di DTW disebabkan oleh hargaharga yang dirasa wajar, keramahtamahan pengelola, dan pelayanan yang diberikan dapat dipercaya.

Implikasi temuan penelitian bagi pengembangan Subak Padanggalak sebagai DTW yaitu lebih memperhatikan layanan DTW bagi pengunjung. Walaupun tingkat persepsi pengunjung masih puas terhadap layanan yang diberikan, namun kondisi ini tidak akan bisa bertahan jika layanan tidak dipertahankan kualitasnya sehingga citra DTW jatuh dan menyebabkan DTW ditinggalkan pengunjung.

\section{SIMPULAN}

Berdasarkan analisis yang dilakukan, maka dapat disimpulkan bahwa (1) Persepsi pengunjung terhadap DTW Subak Padanggalak termasuk kategori baik yang didukung oleh persepsi terhadap atribut DTW yang tergolong baik, persepsi terhadap kualitas layanan tergolong baik, dan tingkat kepuasan terhadap DTW yang juga tergolong puas. Hal ini berarti Subak Padanggalak memenuhi syarat dikembangkan sebagai DTW berbasis pertanian di Kota Denpasar, (2) Atribut DTW dan kualitas layanan DTW berpengaruh signifikan dan positif terhadap kepuasan pengunjung pada DTW Subak Padanggalak yang berarti untuk menjamin kepuasan pengunjung maka Subak Padanggalak wajib menjaga daya tarik pada atribut-atribut subak yang dijadikan atraksi wisata penarik pengunjung dan disertai penyediaan layanan yang berkualitas sebagai standar pengelolaan DTW yang baik.

\section{DAFTAR PUSTAKA}

Chahal H, Devi A. 2015. Destination attributes and destination image relationship in volatile tourist destination: Role of perceived risk. Metamorphosis: A Journal of Management Research. 14(2):1-19.

Diarta IKS, Sarjana IM. 2018. Strategi perekayasaan subak sebagai daya tarik wisata urban [laporan]. Badung: Universitas Udayana

Ghozali I. 2014. Structural Equation Modeling Metode Alternative dengan Partial Least Squares (PLS). Semarang: Universitas Diponogoro

Hasan A. 2015. Tourism Marketing. Yogyakarta: Center for Acadenic Publishing Service.

Kozak M, Rimmington M. 1999. Measuring tourist destination competitiveness: Conceptual considerations and empirical findings. Hospitality Management. 18(1):273-283

Kotler P, Keller KL. 2009. Marketing Management 13th Edition. New Jersey: Pearson Education.

Kusyanda IMRP. 2018. Pengaruh atribut destinasi dan kualitas pelayanan terhadap kepuasan dan niat berkunjung kembali wisatawan ke daya tarik wisata Pantai Melasti Ungasan Kuta Selatan Badung [tesis]. Badung: UNUD.

Lee JH, Hyun DK, Yong JK and Michael S. 2011. The influence of service quality on satisfaction and intention: A gender segmentation strategy. Sport Management Review. 14(1): 54-63

Mill RC, Morrison AM. 2009. The Tourism System. United States of America: Kendall Hunt Publishing Company.

Oliver RL. 2010. Satisfaction: A Behavioral Perspective on The Consumer. New York: Routledge.

Pandža Bajs I. 2015. Tourist perceived value, relationship to satisfaction, and behavioral intentions: The example of the Croatian Tourist Destination Dubrovnik. Journal of Travel Research: 54(1): 122134

Parasuraman A, Zeithaml VA, Berry L. 1985. A conceptual model of service quality and its implications for future research. Journal of Marketing: 49(4): 41-50

Peraturan Daerah Propinsi Bali Daerah Tingkat I Bali Nomor 2 Tahun 2012 tentang Kepariwisataan Budaya Bali

Prayag G, Hosany S, Muskat B, Del Chiappa G. 2017. Understanding the relationships between tourists emotional experiences, perceived overall image, satisfaction, and intention to recommend. Journal of Travel Research: 56(1): 41-54

Putra IND, Pitana IG.2010. Pariwisata Pro Rakyat: Meretas Jalan Mengentaskan Kemiskinan di Indonesia. Jakarta: Kementerian Kebudayaan dan Pariwisata Republik Indonesia

Sholihin M, Ratmono D. 2013. Analisis SEM-PLS dengan WarpPLS 3.0 untuk Hubungan Nonlinier 
dalam Penelitian Ssoial dan Bisnis. Yogyakarta: Andi Yogyakarta.

Sparks R, Westgate M. 2002. Broad based and targeted sponsorship strategies in canadian women ice hokey. International Journal of Sport Marketing and Sponsorship. 4(1): 59-84.

Sugiyono. 2014. Business Research Methods. Alfabeta: Bandung.
Thiumsak T, Ruangkanjanases A. 2016. Factors influencing international visitors to revisit Bangkok, Thailand. Journal of Economics, Business and Management. 4(3): 220-230.

Umar H. 2002. Riset Pemasaran dan Perilaku Konsumen. Jakarta: PT Gramedia Pustaka Utama.

Undang Undang No 10 tahun 2009 tentang Kepariwisataan. 